\title{
Children with cataract and chronic diarrhoea: Cerebrotendinous xanthomatosis
}

\author{
J. R. M. Cruysberg
}

Received: 24 January 2009 /Submitted in revised form: 24 January 2009 / Accepted: 29 January 2009 / Published online: 9 March 2009

(C) SSIEM and Springer 2009

Pierre and co-workers (Pierre et al, 2008) incorrectly cited the article of Kuriyama and co-workers (Kuriyama et al 1991) as reference for the presentation of cerebrotendinous xanthomatosis in childhood with chronic diarrhoea. However, Kuriyama's article does not report chronic diarrhoea at all.

Juvenile cataract associated with chronic diarrhoea in paediatric cerebrotendinous xanthomatosis was originally found by Cruysberg and co-workers (Cruysberg et al 1991, 1995).

\section{References}

Cruysberg JRM, Wevers RA, Tolboom JJM (1991) Juvenile cataract associated with chronic diarrhea in pediatric cerebrotendinous xanthomatosis. Am J Ophthalmol 112: 606-607.

Cruysberg JRM, Wevers RA, Pinckers A, van Engelen BGM, van Spreeken A, Tolboom JJM (1995) Ocular and systemic manifestations of cerebrotendinous xanthomatosis. Am J Ophthalmol 120: 597-604.

Kuriyama M, Fujiyama J, Yoshidome H, et al (1991) Cerebrotendinous xanthomatosis: clinical and biochemical evaluation of eight patients and review of the literature. J Neurol Sci 102: 225-232. doi:10.1016/0022-510X(91)90073-G.

Pierre G, Setchell K, Blyth J, Preece MA, Chakrapani A, McKiernan P (2008) Prospective treatment of cerebrotendinous xanthomatosis with cholic acid therapy. $J$ Inherit Metab Dis. doi: 10.1007/s10545-008-0815-z.

Communicating editor: Georg Hoffmann

Competing interests: None declared

J. R. M. Cruysberg

Radboud University Nijmegen Medical Centre,

Nijmegen, The Netherlands

J. R. M. Cruysberg $(\square)$

400 Ophthalmology, PO Box 9101,

6500 HB Nijmegen, The Netherlands

e-mail: j.cruysberg@ru.nl 